\title{
PENETRATION OF GUINEA-PIG SPERMATOZOA INTO HAMSTER EGGS IN VITRO
}

\author{
R. YANAGIMAGHI \\ Department of Anatomy, University of Hawaii, School of Medicine, \\ Honolulu, Hawaii 96822, U.S.A.
}

(Received 20th September 1971, accepted 4th October 1971)

With some important exceptions (Chang \& Hancock, 1967), fertilization of mammalian eggs is species-specific in that the eggs of a species can be penetrated only by spermatozoa of the same species. The analysis of the species-specificity of fertilization is very difficult when in-vivo systems are used. In-vitro systems, on the other hand, eliminate many factors and enable us to examine directly the interactions between the eggs and spermatozoa.

Barros (1968) inseminated rat eggs in vitro with capacitated golden hamster spermatozoa and found that only one out of 294 eggs had been penetrated. In this egg, two spermatozoa had penetrated the zona pellucida but failed to enter the vitellus. On the other hand, none of 280 mouse eggs inseminated in vitro with capacitated hamster spermatozoa were found to be penetrated. The complete failure of capacitated hamster spermatozoa to enter the zona pellucida of mouse eggs in vitro was previously reported by Yanagimachi (1964). A recent study has shown that neither capacitated nor uncapacitated spermatozoa of the hamster and guinea-pig can penetrate the zona pellucida of rat and mouse eggs in vitro; even when the eggs were freed of the zona pellucida so that the vitelline surface could be directly exposed to the spermatozoa, none of the eggs were penetrated (Yanagimachi, unpublished observations). These results seem to indicate that both the zona pellucida and the vitelline surface of rat and mouse eggs exhibit a strong species-specificity, rejecting the entry of spermatozoa of different species. This communication reports that the vitelline surface of the hamster egg apparently lacks a complete species-specificity and permits the penetration of guinea-pig spermatozoa. The importance of the capacitation of spermatozoa in this process is examined.

Guinea-pig spermatozoa were collected from the cauda epididymidis of fertile males and suspended, at the concentration of 1 to $2 \times 10^{4}$ spermatozoa/ $\mu$ l, in a chemically defined medium (BWW) developed by Biggers, Whitten \& Whittingham (1971). A drop (50 $\mu \mathrm{l})$ of the sperm suspension was put under mineral oil in a watchglass. All, or the vast majority, of the progressively motile spermatozoa freshly suspended in BWW had apparently intact acrosomes (P1. 1, Fig. 1) and were not capable of penetrating guinea-pig eggs in vitro (Yanagimachi, 1972). These acrosome-intact spermatozoa were designated 'uncapacitated.' When a drop of the sperm suspension was incubated under mineral oil for 14 to $18 \mathrm{hr}$ at $37^{\circ} \mathrm{C}$ in a humidified atmosphere of $5 \% \mathrm{CO}_{2}$ in air, approximately 30 to $60 \%$ of the spermatozoa showed vigorous, free move- 
ment and all or almost all of them were devoid of their acrosomal caps (Pl. 1, Fig. 2). Since such spermatozoa were capable of penetrating guinea-pig eggs almost immediately (Yanagimachi, 1972), they were called 'capacitated'.

Unfertilized golden hamster eggs were obtained from oviducts of unbred females, 15 to $16 \mathrm{hr}$ after injection of HCG (Yanagimachi, 1969). The eggs, surrounded by cumulus cells, were washed in two changes of BWW. A group of the eggs was placed in fresh BWW under mineral oil in a Petri dish (intact eggs). Another group of the eggs was treated for 3 min with BWW containing $0.2 \%$ hyaluronidase (bovine testicular, $300 \mathrm{USP}$ units/mg, Nutritional Biochem. Corp.) and $0.2 \%$ pronase (from Streptomyces griseus, grade B, Calbiochem.) to disperse cumulus cells and to dissolve the zona pellucida simultaneously. Such 'naked' (zona-free) eggs were washed in three or four changes of BWW and placed in fresh BWW under mineral oil in another Petri dish. The eggs were kept in the medium for no longer than 30 min before insemination.

Insemination was performed by adding the eggs, with 20 to $50 \mu \mathrm{l}$ of their medium, to a sperm suspension in a watchglass. After mixing the eggs and spermatozoa, the watchglass was incubated at $37^{\circ} \mathrm{C}$ under $5 \% \mathrm{CO}_{2}$ in air. The eggs were examined with a phase-contrast microscope at various intervals after insemination.

When fifty-four intact hamster eggs (five experiments) were inseminated with 'uncapacitated' guinea-pig spermatozoa, the cumulus cells dispersed within 15 min. Although the spermatozoa were constantly colliding with the zona surfaces, none attached permanently. No penetration of spermatozoa into or through the zona or into the vitellus was observed even at $4 \mathrm{hr}$ after insemination. The results were exactly the same when forty-eight intact eggs (five experiments) were inseminated with 'capacitated' spermatozoa.

\section{EXPLANATION OF PLATE 1}

Magnification of all micrographs, approximately $\times 750$ (except for Fig. $3-\times 450$ ).

FIG. 1. 'Uncapacitated' guinea-pig spermatozoa with intact acrosomes.

FIG. 2. A 'capacitated' guinea-pig spermatozoon with an acrosome which has undergone the acrosome reaction.

FIG. 3. A zona-free hamster egg with a group of 'uncapacitated' spermatozoa 's' attached to the vitelline surface, $2 \mathrm{hr}$ after insemination.

Figs. 4 and 5. The second meiotic metaphase spindle (Fig. 4) and cortical granules (Fig. 5 ) in the egg shown in Fig. 3, indicating no activation of the egg by spermatozoa.

Figs. 6 and 7. A hamster egg $40 \mathrm{~min}$ after being inseminated with 'capacitated' guinea-pig spermatozoa, showing egg chromosomes at early anaphase of the second meiotic division (Fig. 6) and a guinea-pig sperm head with distinct signs of swelling (Fig. 7). The arrow indicates a sperm tail.

Figs. 8 to 10. Hamster eggs $1 \mathrm{hr}$ after being inseminated with 'capacitated' guinea-pig. spermatozoa, showing telophase of the second meiotic division (Figs. 8 and 9) and a guinea-pig sperm head further swollen (Fig. 10). m, Midbody in the second meiotic spindle; $1 \mathrm{p}$, possibly the first polar body; $2 \mathrm{p}$, the second polar body. The arrow indicates a sperm tail.

Frg. 11. Two guinea-pig sperm heads in a hamster egg, $2 \mathrm{hr}$ after insemination. The arrows indicate sperm tails.

Frg. 12. A sperm pronucleus (guinea-pig) in hamster egg, $2 \frac{1}{2} \mathrm{hr}$ after insemination. The arrow indicates a sperm tail.

Figs. 13 and 14. A hamster egg photographed at two different focal planes, $3 \mathrm{hr}$ after insemination, showing an egg pronucleus (Fig. 13) and a sperm (guinea-pig) pronucleus (Fig. 14). The arrow indicates a sperm tail. 
PIATE
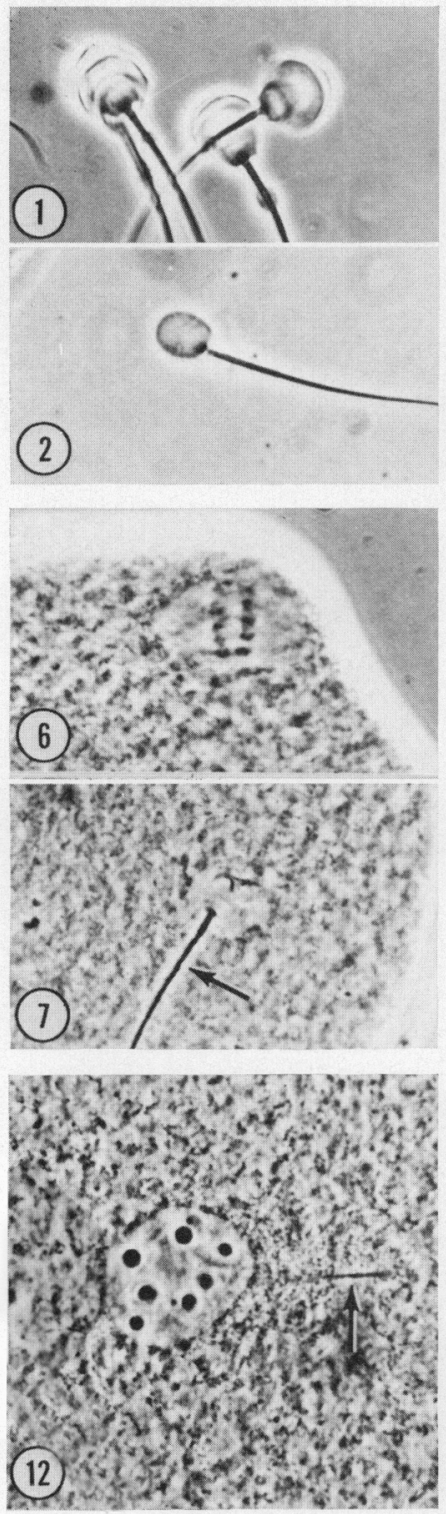
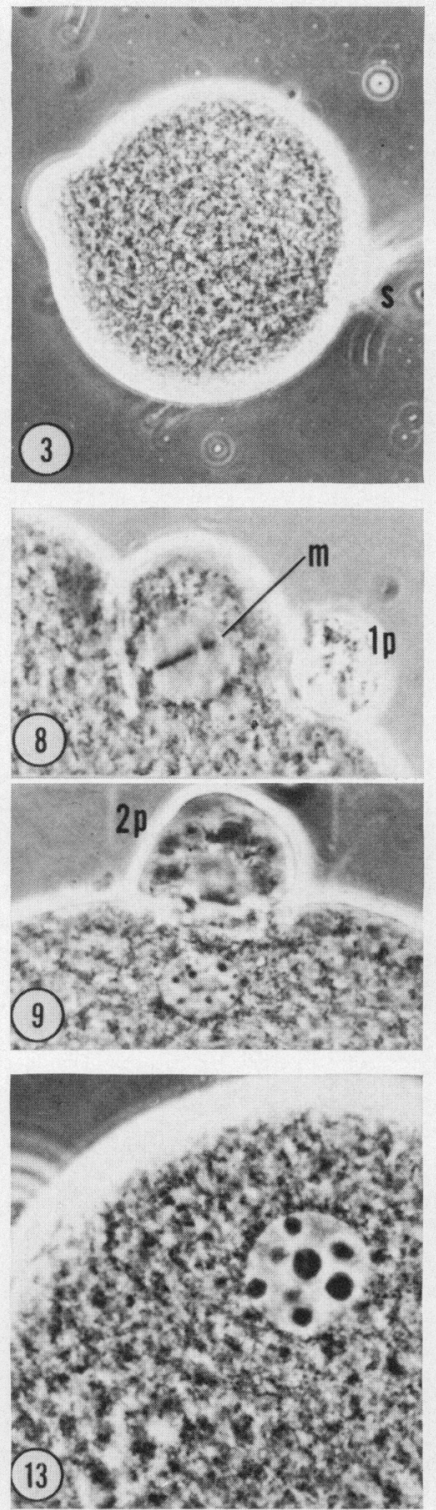
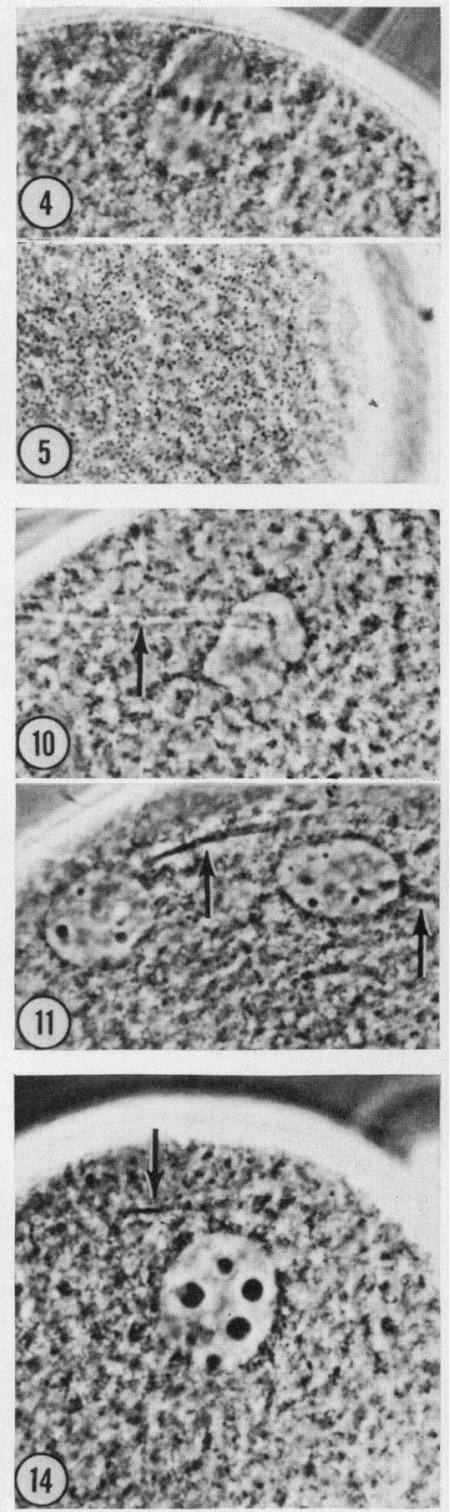
When zona-free eggs were inseminated with 'uncapacitated' spermatozoa, the spermatozoa constantly collided with the vitelline surfaces. Although some attached to the vitelline surface (Pl. 1, Fig. 3), none of forty-five eggs (five experiments) examined $2 \mathrm{hr}$ after insemination showed any signs of activation or sperm penetration (Pl. 1, Figs. 4 and 5). The results were different when zona-free eggs were inseminated with 'capacitated' spermatozoa. Almost immediately after insemination, several spermatozoa attached firmly to the vitelline surface of each egg. Vigorous movement of the tails of some of these spermatozoa quickly diminished. When six eggs were examined 40 min after insemination, the great majority of cortical granules were absent from the eggs, indicating activation of the egg cytoplasm by spermatozoa. The sperm head was distinctly swollen (Pl. 1, Fig. 7) and egg chromosomes were at early anaphase of the second meiotic division (Pl. 1, Fig. 6). Examination of seventyone eggs (eight experiments) between 1 and $3 \mathrm{hr}$ after insemination showed that all were definitely penetrated by spermatozoa (Pl. 1, Figs. 8 to 14). The number of sperm heads that had entered the vitellus and swollen or transformed into male pronuclei varied from one to six per egg.

As reported elsewhere (Yanagimachi, 1972), 'capacitated' guinea-pig spermatozoa very readily penetrate the zona pellucida of guinea-pig eggs in vitro. The complete failure of these spermatozoa to penetrate the zona of the hamster egg suggests that sperm penetration through the zona pellucida involves some species-specific mechanism(s). It has been shown that 'uncapacitated' guineapig spermatozoa fail to enter the vitellus of zona-free eggs of the guinea-pig (Yanagimachi, 1972) or hamster, while 'capacitated' guinea-pig spermatozoa readily penetrate into the vitellus of both guinea-pig (Yanagimachi, 1972) and hamster eggs. These findings strongly suggest that during sperm capacitation the surface (possibly the plasma membrane) of the guinea-pig spermatozoon, like that of the golden hamster spermatozoon (Yanagimachi \& Noda, 1970), undergoes some important physiological changes necessary for fusion with the egg plasma membrane. The apparent lack of a complete species-specificity at the vitelline surface of the hamster egg is noteworthy. Recently, Hanada and Chang (in preparation) found that rat and mouse spermatozoa are capable of penetrating the vitellus of zona-free hamster eggs. If rat and mouse spermatozoa require capacitation before penetration into the vitellus of the zona-free hamster egg, then the zona-free hamster egg could possibly be used as a model to evaluate sperm capacitation in several other species. This would be particularly useful for those species whose the eggs are rather difficult to collect or handle.

This study was supported by grants from the Population Council, the Ford Foundation and U.S. Public Health Service (HD-03402 and HD-02066).

\section{REFERENCES}

BARRos, C. (1968) In vitro capacitation of golden hamster spermatozoa with Fallopian tube fluid of the mouse and rat. F. Reprod. Fert. 17, 203.

Biggers, J. D., Whitten, W. K. \& Whittingham, D. G. (1971) The culture of mouse embryos in vitro. In: Methods in Mammalian Embryology, p. 101, Table 6-5. Ed.J. C. Daniel. W. H. Freeman, San Francisco. 
Ghang, M. G. \& Hancock, J. L. (1967) Experimental hybridization. In: Comparative Aspects of Reproductive Failure, p. 206. Ed. K. Benirschke. Springer, New York.

Yanagimachi, R. (1964) The behavior of hamster sperm to the hamster and mouse ova in vitro. Proc. Vth Int. Congr. Anim. Reprod. Artif. Insem. 7, 292.

YanAGIMACHI, R. (1969) In vitro capacitation of hamster spermatozoa by follicular fluid. 7. Reprod. Fert. 18, 275.

YANAGIMACHI, R. (1972) In vitro fertilization of guinea pig ova. (Abstract). Anat. Rec. 172 (in press).

Yanagimachi, R. \& Noda, Y. D. (1970) Physiological changes in the postnuclear cap region of mammalian spermatozoa; a necessary preliminary to the membrane fusion between sperm and egg cells. F. Ultrastruct. Res. 31, 486. 